\title{
Seleção de fungos micorrízicos arbusculares para o amendoim forrageiro consorciado com braquiária
}

\author{
Elias Melo de Miranda ${ }^{(1)}$, Orivaldo José Saggin Júnior ${ }^{(2)}$ e Eliane Maria Ribeiro da Silva ${ }^{(2)}$ \\ (1)Embrapa Acre, Caixa Postal 321, CEP 69900-970 Rio Branco, AC. E-mail: elias@cpafac.embrapa.br (2)Embrapa Agrobiologia, Caixa \\ Postal 74.505, CEP 23890-000 Seropédica, RJ. E-mail: saggin@cnpab.embrapa.br, eliane@cnpab.embrapa.br
}

Resumo - O objetivo deste trabalho foi selecionar fungos micorrízicos arbusculares (FMAs) eficientes em promover o crescimento de Arachis pintoi e Brachiaria decumbens consorciados, na presença e ausência de espécies de FMAs autóctones. O experimento foi realizado em casa de vegetação na Embrapa Agrobiologia, em Seropédica, RJ. O delineamento experimental foi inteiramente casualizado, com três repetições, e os tratamentos arranjados em fatorial 2x6, tendo sido dois substratos derivados de um Planossolo, não esterilizado e esterilizado, seis tratamentos de inoculação - Acaulospora morrowiae, Entrophospora colombiana, Gigaspora margarita, Glomus clarum, Scutellospora heterogama - e o controle sem inoculação, além de uma testemunha de referência do monocultivo de cada forrageira. Foram realizados três cortes com diferentes intervalos, e o experimento foi conduzido até que a competição da gramínea e o esgotamento do substrato inviabilizaram a permanência da leguminosa no consórcio. Houve benefício dos FMAs na produção de matéria seca das plantas do amendoim forrageiro, e G. clarum foi a espécie mais eficiente. A utilização de mudas colonizadas por FMAs eficientes contribui para o estabelecimento e crescimento inicial das plantas do amendoim forrageiro e aumenta a sua capacidade competitiva com a braquiária.

Termos para indexação: Arachis pintoi, Brachiaria decumbens, pastagens consorciadas.

\section{Selection of arbuscular mycorrhizal fungi for the forage peanut intercropped with signal grass}

\begin{abstract}
The objective of this work was to evaluate and select efficient arbuscular mycorrhizal fungi (AMF) to promote growth of the intercropped Arachis pintoi and Brachiaria decumbens, in the presence and absence of competing autochthonous AMF. The experiment was performed under greenhouse conditions at Embrapa Agrobiologia, in Seropédica, RJ. The experimental design was completely randomized with three repetitions, in a 2x6 factorial arrangement, with two substrates (non sterile and sterile) derivative of a Fragiudult (Planosol) and six treatments of inoculation (Acaulospora morrowiae, Entrophospora Colombiana, Gigaspora margarita, Glomus clarum, Scutellospora heterogama, and a noninoculated control); besides a monoculture of each forage as a reference control. Three cuts were made during the experimental period, at different intervals, until the competition and substrate depletion made the permanence of the leguminous unviable in the consortium. Benefits were observed for AMF inoculation to the production of A. pintoi dry matter, being G. clarum the more efficient species. The use of seedlings efficiently colonized by AMF facilitates the establishment and initial growth of forage peanuts plants, increasing their competitive capacity with Brachiaria.
\end{abstract}

Index terms: Arachis pintoi, Brachiaria decumbens, mixed pastures.

\section{Introdução}

A braquiária (Brachiaria decumbens Stapf) é uma das forrageiras mais utilizadas, principalmente no Brasil Central, que apresenta boa adaptação a solos ácidos, alta tolerância a $\mathrm{Al}$ e baixa exigência em $\mathrm{P}$ e Ca. Entre suas características agronômicas favoráveis, destacam-se: o elevado rendimento de matéria seca, a tolerância à baixa fertilidade dos solos e a elevada agressividade (Bomfim et al., 2003). Esta última característica pode ser um problema para a associação com outras espécies, pois dificulta a consorciação com leguminosas rasteiras.

O amendoim forrageiro (Arachis pintoi Krap. \& Greg.) éuma leguminosa herbácea perene, recomendada para cobertura do solo em diversos agrossistemas e para a consorciação com gramíneas em pastagens. A importância dessa leguminosa vem crescendo nas regiões tropicais, tanto pela qualidade de sua forragem quanto pelos benefícios que proporciona ao sistema

Pesq. agropec. bras., Brasília, v.43, n.9, p.1185-1191, set. 2008 
solo-planta-animal. Em razão de seu crescimento rasteiro e estolonífero, o amendoim forrageiro pode ser consorciado com gramíneas de crescimento vigoroso, desde de que sejam adotadas práticas de manejo para reduzir a competição sobre esta leguminosa (Andrade et al., 2006).

O consórcio de espécies de braquiária com o amendoim forrageiro tem sido recomendado para várias localidades, com resultados positivos (Valentim et al., 2001). Entretanto, há relatos de que estas gramíneas podem causar efeitos alelopáticos (Souza Filho et al., 1997, 2005; Souza et al., 2006).

Segundo Cadisch et al. (1994), a introdução de leguminosas é uma das principais ferramentas para prevenir a degradação das pastagens. Elas melhoram a qualidade da dieta animal pelo consumo direto e, ao transferir $\mathrm{N}$ para a gramínea associada, melhoram os atributos forrageiros, como teor de proteína e capacidade produtiva, e aumentam a capacidade de suporte das pastagens. Silva \& Saliba (2007) relatam resultados de vários estudos de consórcio de braquiária com leguminosas, em que houve incrementos tanto na produção total de biomassa, em relação ao sistema de monocultura, como no ganho de peso dos animais. Outros resultados positivos da consorciação de braquiárias com o amendoim forrageiro foram relatados por Suárez-Vásquez et al. (1992), Argel \& Villarreal (1998) e Valentim et al. (2001). O estabelecimento e manutenção de leguminosas tropicais perenes, consorciadas com gramíneas tropicais, têm apresentado muitos insucessos, e sua baixa persistência sob pastejo representa o desafio mais importante à pesquisa.

Os fungos micorrízicos arbusculares (FMAs) são organismos importantes na nutrição de plantas. Em solos de média a baixa fertilidade, contribuem para aumentar a eficiência da absorção, o que auxilia no transporte de nutrientes, principalmente daqueles de baixa mobilidade no solo, como P, Zn e $\mathrm{Cu}$, tornando-os mais disponíveis às plantas. Santos et al. (2001) analisaram os efeitos do N, P e do FMA Glomus etunicatum na participação de $B$. brizanta e $A$. pintoi, na matéria seca produzida por estas espécies em consórcio. Foi observado que a gramínea não foi favorecida pelo FMA, mas sim pela aplicação de N e P, enquanto com a leguminosa ocorreu o contrário, mas na ausência da fertilização. Esses autores consideraram o efeito de apenas uma espécie de FMA (G. etunicatum), mas sabe-se que as plantas podem se beneficiar de forma diferenciada, a depender do funcionamento e eficiência da simbiose, de diferentes combinações de espécies de fungos com a planta hospedeira. Portanto, o conhecimento da interação entre as plantas cultivadas e os diferentes fungos micorrízicos é importante para o desenvolvimento de sistemas de manejo mais sustentáveis. $\mathrm{O}$ amendoim forrageiro pode se adequar bem a este propósito, principalmente se for introduzido no sistema por meio de mudas com inoculação de FMAs eficientes.

Este trabalho teve o objetivo de selecionar, entre cinco espécies de FMA, as mais eficientes em aumentar a produção de matéria seca da parte aérea de $A$. pintoi e $B$. decumbens consorciados, na presença e ausência de competição com espécies de FMAs autóctones, em diferentes intervalos de corte.

\section{Material e Métodos}

O experimento foi estabelecido em casa de vegetação não climatizada da Embrapa Agrobiologia, em Seropédica, RJ, com substrato coletado em seu campo experimental, em um Planossolo de textura arenosa, com as seguintes características químicas: $\mathrm{pH}\left(\mathrm{H}_{2} \mathrm{O}\right) 6,6 ; \mathrm{Al}^{3+}, 0 \mathrm{cmol}_{\mathrm{c}} \mathrm{dm}^{-3} ; \mathrm{Ca}, 1,4 \mathrm{cmol}_{\mathrm{c}} \mathrm{dm}^{-3}$; $\mathrm{Mg}, 0,8 \mathrm{cmol}_{\mathrm{c}} \mathrm{dm}^{-3}$; P, $9 \mathrm{mg} \mathrm{dm}^{-3}$ e K, $69 \mathrm{mg} \mathrm{dm}^{-3}$ (Embrapa, 1997); matéria orgânica, 11,4 $\mathrm{g} \mathrm{kg}^{-1}$; C (Walkley \& Black, 1934), 6,6 $\mathrm{g} \mathrm{kg}^{-1}$ e N (Alves et al., 1994), $0,88 \mathrm{~g} \mathrm{~kg}^{-1}$.

O substrato não recebeu fertilização adicional e foi separado em duas partes; uma delas foi submetida ao processo de esterilização por autoclavagem (exposição por duas vezes a $120^{\circ} \mathrm{C}$ e pressão úmida de $1 \mathrm{kgf} \mathrm{cm}^{-2}$, por $60 \mathrm{~min}$, em dias consecutivos). Deixou-se o solo secar e descansar por uma semana após a autoclavagem, para estabilizar os teores de manganês e, então, os vasos foram preenchidos com $5 \mathrm{~kg}$ do substrato.

Odelineamento experimentalusado foi o inteiramente casualizado, e os tratamentos foram arranjados em esquema fatorial $2 \times 6$, com duas condições de substrato (não esterilizado (NE) e esterilizado (ES) por autoclavagem), e seis tratamentos de inoculação nas mudas de amendoim forrageiro (com cinco espécies de FMAs procedentes da Coleção de Fungos Micorrízicos Arbusculares da Embrapa Agrobiologia, e mais o controle sem inóculo). As espécies de FMA avaliadas foram: Acaulospora morrowiae Spain \& Shenck (CNPAB 019), Entrophospora colombiana 
Spain \& Shenck (CNPAB 015), Gigaspora margarita Becker \& Hall (CNPAB 001), Glomus clarum Nicolson \& Schenck (CNPAB 005) e Scutellospora heterogama (Nicolson \& Gerd.) Walker \& Sanders (CNPAB 002). Além destes doze tratamentos, foram incluídos dois controles adicionais, que funcionaram como testemunhas de referência do monocultivo do amendoim forrageiro e da braquiária, em substrato não esterilizado e sem inoculação exógena, ou seja, apenas com os FMAs autóctones presentes no substrato. O experimento foi instalado com 14 tratamentos e 3 repetições, no total de 42 parcelas (vasos).

Em todos os vasos, a braquiária (Brachiaria decumbens Stapf cv. Basilisk) foi semeada no dia 28/6/2005, com 38 dias de antecedência ao transplante das mudas do amendoim. Este procedimento foi adotado com o intuito de simular uma situação de introdução desta leguminosa em pastagens já estabelecidas. Foram plantadas oito sementes por vaso, desinfestadas com hipoclorito de sódio a $2 \%$ durante 20 min e, após 15 dias, foi feito um desbaste, tendo-se deixado duas plantas por vaso. Foi plantada uma muda de amendoim forrageiro (Arachis pintoi Krap. \& Greg. cv. Amazônia) por vaso, com idade de 120 dias no dia 5/8/2005, arranjadas entre as plantas de braquiária. As mudas já haviam sido submetidas à inoculação de FMAs, e apresentavam, por ocasião do transplantio, densidades de esporos no substrato e taxas de colonização radicular conforme mostrado na Tabela 1.

As mudas foram produzidas com sementes provenientes da Embrapa Acre (cv. Amazônia, em processo de lançamento), em bandejas de isopor de 72 células, cada uma com capacidade para $100 \mathrm{~cm}^{3}$ de substrato, que foi o mesmo utilizado no presente experimento de consórcio, submetido ao mesmo procedimento de esterilização. Antes do plantio, o pericarpo das sementes foi retirado, tendo-se plantado apenas as amêndoas, que também foram submetidas a processo de desinfestação com hipoclorito de sódio a $2 \%$, por $20 \mathrm{~min}$. Todas as sementes foram tratadas, por ocasião do plantio, com a estirpe de rizóbio BR 1405, veiculada em meio líquido.

O tratamento de inoculação dos FMAs foi realizado diretamente nas bandejas, tendo-se aplicado $1 \mathrm{~cm}^{3}$ de solo-inóculo por célula, com pedaços de raízes infectadas, hifas e, em média, 50 esporos por espécie. $\mathrm{O}$ inóculo foi colocado em orifícios com cerca de três centímetros de profundidade, aberto no centro da célula, antes da semeadura. As densidades de esporos nos substratos e as taxas de colonização radicular por espécie, após o estabelecimento da associação micorrízica, são mostradas na Tabela 1. Não foi realizada nova inoculação por ocasião do transplantio das mudas. No tratamento-controle (sem inóculo) foi colocado $1 \mathrm{~cm}^{3}$ de solo-inóculo autoclavado; em seguida, foi adicionado nas células de todos os tratamentos $1 \mathrm{~mL}$ de filtrado dos solos-inóculos, isentos de propágulos de FMAs, com a finalidade de equilibrar a população microbiana acompanhante do inóculo micorrízico, em tratamentos.

A reposição da água evapotranspirada no experimento foi realizada por irrigação manual, com água deionizada, pela manhã e à tarde, conforme a necessidade.

No dia 16/9/2005, 42 dias após o transplantio do amendoim, foi realizado corte de uniformização da fitomassa das duas espécies, postergado até que não mais houvesse o risco de morte das plantas, pois foi bastante drástico, com forte redução da aérea foliar. Posteriormente foram realizados mais três cortes em: $1 / 11 / 2005,12 / 1 / 2006$ e 22/5/2006, correspondentes a intervalos de 45, 72 e 130 dias, respectivamente, todos realizados à altura de $5 \mathrm{~cm}$ do substrato. $\mathrm{O}$ ensaio foi conduzido até que a competição da braquiária e o esgotamento do substrato inviabilizaram a permanência do amendoim forrageiro no sistema.

Foi avaliada a produção de matéria seca da parte aérea das duas espécies, em cada corte, nos substratos NE e ES. Os dados foram submetidos a testes de normalidade e homogeneidade de variância e, quando não atenderam a um destes requisitos, foram transformados para $(\mathrm{x}+1)^{0,5} \mathrm{e}$, então, submetidos

Tabela 1. Densidade média de esporos, no substrato das mudas de amendoim forrageiro, e taxa de colonização das raízes por espécies de FMA em substrato esterilizado, e por espécies autóctones em substrato não esterilizado (NE), 120 dias após o plantio.

\begin{tabular}{lcc}
\hline Tratamento & $\begin{array}{c}\mathrm{N}^{\mathbf{0}} \text { de esporos } \\
100 \mathrm{~cm}^{-3}\end{array}$ & $\begin{array}{c}\text { Colonização } \\
\text { radicular (\%) }\end{array}$ \\
\hline Acaulospora morrowiae & 9.907 & 21,8 \\
Entrophospora colombiana & 26.494 & 14,5 \\
Gigaspora margarita & 297 & 10,8 \\
Glomus clarum & 30.394 & 61,0 \\
Scutellospora heterogama & 369 & 7,5 \\
FMAs autóctones (substrato NE) & 286 & 38,0 \\
\hline
\end{tabular}

Pesq. agropec. bras., Brasília, v.43, n.9, p.1185-1191, set. 2008 
à análise de variância e ao teste de comparação de médias de Scott-Knott (1974), a 5\% de probabilidade, pelo SISVAR para Windows versão 4.6.

\section{Resultados e Discussão}

A produção de matéria seca da parte aérea (MSPA) do amendoim forrageiro e da braquiária está apresentada na Tabela 2. No primeiro corte, realizado aos 45 dias após o corte de padronização, não houve diferença entre as espécies de FMA e o controle sem inóculo (SI), no substrato não esterilizado (NE), com exceção de G. clarum, que produziu mais do que o dobro dos demais tratamentos, com diferença significativa. No substrato esterilizado (ES), destacaram-se os tratamentos com Acaulospora morrowiae, Entrophospora colombiana e Glomus clarum, significativamente superiores às espécies Gigaspora margarita e Scutelospora heterogama, que não diferiram do tratamento SI.

Aprodução de MSPAda braquiária, no primeiro corte, no substrato NE, foi uniforme entre os tratamentos, e não diferiu significativamente do controle SI (Tabela 2). Nesta situação, em que os FMAs autóctones ocuparam os sítios de colonização das raízes desde a germinação da braquiária, não era esperado que houvesse resposta à inoculação, principalmente em razão de esta gramínea formar simbiose eficiente com um elevado número de espécies de FMA (Howeler et al., 1987), e de as espécies avaliadas terem sido introduzidas posteriormente, com a colonização dos fungos autóctones já estabelecida.

No substrato ES, a braquiária respondeu aos tratamentos de inoculação, que foram superiores ao controle SI. O fungo que se destacou foi S. heterogama, tendo sido superior aos demais tratamentos, seguido de G. margarita, G. clarum e A. morrowiae, que não diferiram entre si, e de E. colombiana, que foi superior apenas ao controle SI. A magnitude das respostas em percentual sobre o controle SI foi bastante elevada: $463 \%$ para $S$. heterogama, $341 \%$ para G. margarita, $318 \%$ para G. clarum, $262 \%$ para A. morrowiae e $209 \%$ para E. colombiana. Estes índices foram muito superiores ao encontrado por Saif (1987), que estudou a braquiária em um Latossolo ácido da Colômbia e obteve $94 \%$ de resposta à inoculação de uma mistura de Glomus manihotis, Acaulospora longula e E. colombiana. Os resultados obtidos por Saif e no presente trabalho são indicativos de que mesmo plantas consideradas pouco dependentes dos FMAs, como as

Tabela 2. Produção de matéria seca da parte aérea do amendoim forrageiro e da braquiária (grama por vaso), no primeiro, segundo e terceiro corte, em razão das espécies de FMA e do controle sem inóculo, em substrato não esterilizado (NE) e esterilizado $(\mathrm{ES})^{(1)}$.

\begin{tabular}{|c|c|c|c|c|}
\hline \multirow[t]{2}{*}{ Espécie de FMA } & \multicolumn{2}{|c|}{ Amendoim forrageiro } & \multicolumn{2}{|c|}{ Braquiária } \\
\hline & Substrato NE & Substrato ES & Substrato NE & Substrato ES \\
\hline & \multicolumn{4}{|c|}{ Primeiro corte } \\
\hline Acaulospora morrowiae & $0,37 \mathrm{bB}$ & $1,07 \mathrm{aA}$ & $2,75 \mathrm{aB}$ & $5,34 \mathrm{bA}$ \\
\hline Entrophospora colombiana & $0,45 \mathrm{bB}$ & $1,03 \mathrm{aA}$ & $2,35 \mathrm{aB}$ & $4,26 \mathrm{cA}$ \\
\hline Gigaspora margarita & $0,38 \mathrm{bA}$ & $0,58 \mathrm{bA}$ & $2,59 \mathrm{aB}$ & $6,96 \mathrm{bA}$ \\
\hline Glomus clarum & $1,16 \mathrm{aA}$ & $0,77 \mathrm{aA}$ & $2,46 \mathrm{aB}$ & $6,48 \mathrm{bA}$ \\
\hline Scutellospora heterogama & $0,39 \mathrm{bA}$ & $0,53 \mathrm{bA}$ & $2,47 \mathrm{aB}$ & $9,44 \mathrm{aA}$ \\
\hline \multirow[t]{2}{*}{ Controle sem inóculo } & $0,22 \mathrm{bA}$ & $0,21 \mathrm{bA}$ & $2,36 \mathrm{aA}$ & $2,04 \mathrm{dA}$ \\
\hline & \multicolumn{4}{|c|}{ Segundo corte } \\
\hline Acaulospora morrowiae & $0,22 \mathrm{bA}$ & $0,51 \mathrm{aA}$ & $3,90 \mathrm{aA}$ & $4,43 \mathrm{bA}$ \\
\hline Entrophospora colombiana & $0,24 \mathrm{bA}$ & $0,32 \mathrm{aA}$ & $3,27 \mathrm{aA}$ & $4,50 \mathrm{bA}$ \\
\hline Gigaspora margarita & $0,70 \mathrm{bA}$ & $0,40 \mathrm{aA}$ & $3,07 \mathrm{aB}$ & $5,70 \mathrm{bA}$ \\
\hline Glomus clarum & $0,12 \mathrm{aA}$ & $0,34 \mathrm{aA}$ & $3,13 \mathrm{aB}$ & $6,00 \mathrm{bA}$ \\
\hline Scutellospora heterogama & $0,22 \mathrm{bA}$ & $0,26 \mathrm{aA}$ & $3,33 \mathrm{aB}$ & $5,30 \mathrm{bA}$ \\
\hline \multirow[t]{2}{*}{ Controle sem inóculo } & $0,28 \mathrm{bA}$ & $0,12 \mathrm{aA}$ & $2,97 \mathrm{aB}$ & $9,70 \mathrm{aA}$ \\
\hline & \multicolumn{4}{|c|}{ Terceiro corte } \\
\hline Acaulospora morrowiae & $0,01 \mathrm{aA}$ & $0,000 \mathrm{aA}$ & $13,69 \mathrm{aA}$ & $8,99 \mathrm{aB}$ \\
\hline Entrophospora colombiana & $0,08 \mathrm{aA}$ & $0,000 \mathrm{aA}$ & $13,09 \mathrm{aA}$ & $11,24 \mathrm{aA}$ \\
\hline Gigaspora margarita & $0,13 \mathrm{aA}$ & $0,012 \mathrm{aA}$ & $10,89 \mathrm{aA}$ & $9,25 \mathrm{aA}$ \\
\hline Glomus clarum & $0,06 \mathrm{aA}$ & $0,013 \mathrm{aB}$ & $10,85 \mathrm{aA}$ & $10,22 \mathrm{aA}$ \\
\hline Scutellospora heterogama & $0,03 \mathrm{aA}$ & $0,000 \mathrm{aA}$ & $10,19 \mathrm{aA}$ & $8,69 \mathrm{aA}$ \\
\hline Controle sem inóculo & $0,03 \mathrm{aA}$ & $0,000 \mathrm{aA}$ & $10,80 \mathrm{aA}$ & $14,26 \mathrm{aA}$ \\
\hline
\end{tabular}


braquiárias (Cordeiro et al., 2005), podem se beneficiar da simbiose e apresentar respostas à inoculação em solos pobres, principalmente naqueles com elevada capacidade de retenção de fosfatos.

No segundo corte do amendoim, realizado com 72 dias de intervalo, as plantas de todos os tratamentos de inoculação tiveram uma visível redução no acúmulo de matéria seca (MS), nos dois substratos, provavelmente em razão do esgotamento de algum nutriente e da competição com a braquiária (Tabela 2).

No substrato NE, G. clarum foi novamente a espécie que proporcionou a maior produção de MS, superior aos demais tratamentos $(p<0,05)$, e ratificou sua maior capacidade competitiva e eficiência em relação aos FMAs autóctones. No substrato ES, observou-se um equilíbrio entre as plantas, sem diferenças significativas entre os tratamentos. $\mathrm{O}$ desempenho de cada espécie de FMA, entre os substratos, também foi equilibrado, e não ocorreram interações significativas.

A produção de MSPA da braquiária, obtida no segundo corte no substrato NE, também se manteve equilibrada e não foi constatada diferença significativa entre os tratamentos. Houve um ligeiro aumento em relação à MSPA produzida no primeiro corte, em razão do maior intervalo entre os cortes (Tabela 2). As espécies A. morrowiae e E. colombiana promoveram produção de MS equivalente, nos dois substratos, e não ocorreram interações significativas. Nos demais tratamentos, as plantas cresceram mais no substrato ES, com diferenças significativas.

No substrato ES, a produção de MSPA da maioria dos tratamentos foi menor em relação ao primeiro corte, principalmente no caso de $S$. heterogama, com redução de $44 \%$ na MS produzida. No controle sem inóculo, houve aumento na produção de MS de 79\%. Isto evidencia o esgotamento nutricional do substrato da maioria dos vasos de cultivo, onde as plantas de braquiária com inóculo já haviam apresentado maior crescimento, bem como a competição dos FMAs pelos fotoassimilados produzidos pela gramínea em um substratojá exaurido.As plantas controle, como aumento do intervalo de corte, tiveram maior desenvolvimento do sistema radicular e, conseqüentemente, maiores condições de absorver os nutrientes disponíveis, não usados anteriormente em razão da baixa taxa de crescimento das plantas. Este efeito não foi verificado nas plantas controle do amendoim forrageiro, em razão da maior capacidade competitiva da braquiária.
O terceiro corte do amendoim forrageiro, realizado com intervalo de 130 dias, expôs o amendoim à severa competição com a braquiária, cujo resultado foi a redução drástica da MS e sua saída do sistema, no substrato ES (Tabela 2), em que permaneceram vivas apenas as plantas com inoculação de G. clarum e G. margarita, o que indica que essas espécies tornaram as plantas de amendoim mais resistentes à competição da braquiária e possibilitaram aumento da permanência das plantas no consórcio. As plantas com inoculação de G. clarum produziram maior quantidade de MS nos dois substratos, em todos os cortes realizados, o que indica maior eficiência simbiótica entre esse FMA e o amendoim forrageiro.

No substrato NE, não houve diferenças significativas entre os tratamentos, todavia, G. clarum continuou a promover maior produção de $\mathrm{MS}$, embora não $\mathrm{o}$ suficiente para causar diferença significativa entre os tratamentos. As plantas de amendoim cultivadas nesse substrato sobreviveram até o terceiro corte, independentemente dos tratamentos de inoculação, embora com forte queda na produção de MS. Provavelmente, o efeito alelopático da braquiária (Souza et al., 2006) sobre o amendoim forrageiro pode ser atenuado pela comunidade microbiana do solo presente no substrato NE.

O efeito da competição da braquiária sobre o amendoim em plantio consorciado também foi demonstrado por Santos et al. (2001), que observaram que enquanto a gramínea aumentou a produção de MS, a leguminosa foi suprimida com a elevação das doses de fósforo. A gramínea mostrou-se mais agressiva e, portanto, mais competitiva pelos nutrientes, além de luz e água, principalmente quando se aplicou a adubação nitrogenada. No presente estudo, esses mesmos efeitos foram observados sem a aplicação de $\mathrm{N}$ ou $\mathrm{P}$.

No terceiro corte da braquiária (Tabela 2), com intervalo de 130 dias, verificou-se equilíbrio entre todos os tratamentos de inoculação, nos dois substratos, sem diferenças significativas entre os tratamentos. Isso é indicação de que após o pleno restabelecimento da braquiária - proporcionado pelo maior intervalo de corte e disponibilidade dos nutrientes reciclados com a decomposição das raízes dos cortes anteriores - ocorre a anulação do diferencial de eficiência simbiótica entre as espécies de FMA, e a micorriza deixa de exercer um papel nutricional significativo para essa gramínea, principalmente em razão da sua alta capacidade de 
absorver nutrientes (Bianco et al., 2005). Nesse corte também ocorreu aumento significativo na produção de MS, em todos os tratamentos, que foi proporcional ao aumento no intervalo de corte.

Os resultados obtidos neste trabalho estão de acordo com o relatado por Santos et al. (2001). Ao estudar o efeito de $\mathrm{N}, \mathrm{P}$ e micorriza sobre o consórcio de $A$. pintoi com $B$. brizantha, esses autores verificaram que a inoculação de FMA não favoreceu a participação da gramínea no consórcio. Além disso, na leguminosa, o efeito desse fator foi significativo na ausência de N, como foi o caso deste trabalho.

A acentuada redução na produção de MS, nos dois substratos, em relação aos primeiros cortes e à saída do sistema das plantas de amendoim, no terceiro corte no substrato ES, pode ser atribuída ao efeito competitivo e até mesmo de possíveis efeitos alelopáticos da braquiária, conforme foi encontrado por Souza et al. (2006).

Os efeitos negativos da competição da braquiária ficam evidentes, quando se analisam as plantas de amendoim que foram cultivadas nas mesmas condições daquelas consorciadas, porém em monocultivo (testemunhas de referência), que continuaram a produzir MS similar ou mesmo maiores do que nos primeiros cortes. Isto é mostrado na Tabela 3, onde se constata que, no segundo e terceiro cortes, as plantas do amendoim em monocultivo produziram as maiores quantidades de MS, estatisticamente iguais entre si e superiores à produzida no primeiro corte. $\mathrm{O}$ mesmo fato se verificou nas plantas de braquiária em monocultivo, que produziram a maior quantidade de MS no terceiro corte, com diferenças significativas em relação aos cortes anteriores. Esses resultados também podem ser explicados pela reciclagem de nutrientes das raízes de cortes anteriores e pela alta capacidade da braquiária de absorver os nutrientes, mesmo em substratos de fertilidade reduzida (Bianco et al., 2005).

Tabela 3. Matéria seca da parte aérea (grama por vaso) produzida pelo amendoim forrageiro e pela braquiária, em consórcio e em monocultivo, estabelecidos em substrato não esterilizado $^{(1)}$.

\begin{tabular}{cccccc}
\hline \multirow{2}{*}{ Corte } & \multicolumn{2}{c}{ Amendoim forrageiro } & & \multicolumn{2}{c}{ Braquiária } \\
\cline { 2 - 3 } \cline { 5 - 6 } & Monocultivo & Consórcio & & Monocultivo & Consórcio \\
\hline $1^{\underline{\underline{o}}}$ & $2,93 \mathrm{bA}$ & $0,50 \mathrm{aB}$ & & $2,48 \mathrm{bA}$ & $2,50 \mathrm{cA}$ \\
$2^{\underline{\underline{o}}}$ & $5,33 \mathrm{aA}$ & $0,30 \mathrm{aB}$ & & $2,90 \mathrm{bA}$ & $3,28 \mathrm{bA}$ \\
$3^{\underline{0}}$ & $4,73 \mathrm{aA}$ & $0,06 \mathrm{bB}$ & & $10,27 \mathrm{aA}$ & $11,58 \mathrm{aA}$ \\
\hline
\end{tabular}

${ }^{(1)}$ Médias seguidas por letras iguais, minúsculas nas colunas e maiúsculas nas linhas, na mesma espécie, não diferem entre si pelo teste de Scott-Knot, a $5 \%$ de probabilidade.
A permanência dessa leguminosa no sistema consorciado é condicionada à adoção de práticas de manejo que reduzam a competição da gramínea (Andrade et al., 2006) ou que aumentem a sua tolerância à competição, conforme demonstrado neste trabalho, por meio do uso de mudas micorrizadas, que podem ajudar na fase de estabelecimento e crescimento inicial das plantas. Aqueda no rendimento de MS do amendoim forrageiro, à medida que aumentou o intervalo de corte, indica que a braquiária, no campo, deve ser submetida a uma maior pressão de pastejo, para que a proporção da leguminosa no consórcio se mantenha ou até mesmo aumente (Fisher \& Cruz, 1995).

\section{Conclusões}

1. Glomus clarum proporciona maior produção de matéria seca em plantas de amendoim forrageiro consorciadas com braquiária, em presença de fungos micorrízicos arbusculares (FMAs) autóctones, nos intervalos de corte de 45 e 72 dias.

2. Acaulospora morrowiae, Entrophospora colombiana e Glomus clarum são as espécies mais eficientes em promover o crescimento do amendoim forrageiro consorciado com braquiária, na ausência de FMAs autóctones, no intervalo de corte de 45 dias.

3. Scutellospora heterogama proporciona maior produção de matéria seca na braquiária consorciada com o amendoim forrageiro, na ausência de FMAs autóctones, no intervalo de corte de 45 dias.

4. Os fungos micorrízicos autóctones são tão eficientes em promover a produção de matéria seca da braquiária consorciada quanto os fungos introduzidos.

5. Intervalos de corte maiores que 45 dias são prejudiciais à estabilidade da consorciação e favorecem a predominância da gramínea.

\section{Referências}

ALVES, B.J.R.; SANTOS, J.C.F. dos; URQUIAGA, S.; BODDEY, R.M. Métodos de determinação do nitrogênio em solo e planta. In: HUNGRIA, M.; ARAUJO, R.S. (Ed.). Manual de métodos empregados em estudos de microbiologia agrícola. Brasília: Embrapa-SPI; Goiânia: Embrapa-Cnpaf; Londrina: EmbrapaCNPSo, 1994. p.449-467. (Embrapa-Cnpaf. Documentos, 46)

ANDRADE, C.M.S. de; GARCIA, R.; VALENTIM, J.F.; PEREIRA, O.G. Grazing management strategies for massaigrassforage peanut pastures. 1. Dynamics of sward condition and botanical composition. Revista Brasileira de Zootecnia, v.35, p.334-342, 2006. 
ARGEL, P.; VILLARREAL, M. Nuevo maní forrajero perenne (Arachis pintoi Krap. y Greg. nom. mud.) (CIAT 18744): leguminosa herbácea para alimentación animal, el mejoramiento y conservación del suelo y el embellecimiento del paisaje. San José: Ministério de Agricultura y Ganadería de Costa Rica, 1998. 23p.

BIANCO, S.; TONHÃO, M.A.R.; PITELLI, R.A. Crescimento e nutrição mineral de capim braquiária. Planta Daninha, v.23, p.423-428, 2005.

BOMFIM, E.R.P.; PINTO, J.C.; SALVADOR, N.; MORAIS, A.R. de; ANDRADE, I.F. de; ALMEIDA, O.C. de. Efeito do tratamento físico associado à adubação em pastagens degradadas de braquiária, nos teores de proteína bruta, fibra em detergente neutro e fibra em detergente ácido. Ciência e Agrotecnologia, v.27, p.912-920, 2003.

CADISH, G.; SCHUNKE, R.M.; GILLER, K.E. Nitrogen cycling in a pure grass pasture and a grass-legume misture on a Red Latosol in Brazil. Tropical Grasslands, v.28, p.43-52, 1994.

CORDEIRO, M.A.S.; CARNEIRO, M.A.C.; PAULINO, H.B.; SAGGIN JÚNIOR, O.J. Colonização e densidade de esporos de fungos micorrízicos em dois solos do Cerrado sob diferentes sistemas de manejo. Pesquisa Agropecuária Tropical, v.35, p.147-153, 2005.

FISHER, M.J.; CRUZ, P. Algunos aspectos de la ecofisiología de Arachis pintoi. In: KERRIDGE, P.C. (Ed.). Biología y agronomía de especies forrajeras de Arachis. Cali: CIAT, 1995. p.56-75.

HOWELER, R.H.; SIEVERDING, E.; SAIF, S. Practical aspects of mycorrhizal technology in some tropical crops and pastures. Plant and Soil, v.100, p.249-283, 1987.

SAIF, S.R. Growth responses of tropical forage plant species to vesicular-arbuscular mycorrhizae. Plant and Soil, v.97, p.25-35, 1987.
SANTOS, I.P.A. dos; PINTO, J.C.; SIQUEIRA, J.O.; MORAIS, A.R. de; CURI, N.; EVANGELISTA, A.R. Resposta a fósforo, micorriza e nitrogênio de braquiarão e amendoim forrageiro consorciados. 1. Rendimento de matéria seca da parte aérea e da raiz. Ciência e Agrotecnologia, v.25, p.1206-1215, 2001.

SCOTT, A.J.; KNOTT, M. A Cluster analysis method for grouping means in the analysis of variance. Biometrics, v.30, p.507-512, 1974.

SILVA, J.J. da; SALIBA, E. de O.S. Pastagens consorciadas: uma alternativa para sistemas extensivos e orgânicos. Veterinária e Zootecnia, v.14, p.8-18, 2007.

SOUZA, L.S.; VELINI, E.D.; MARTINS, D.; ROSOLEM, C.A. Efeito alelopático de capim-braquiária (Brachiaria decumbens) sobre o crescimento inicial de sete espécies de plantas cultivadas. Planta Daninha, v.24, p.657-668, 2006.

SOUZA FILHO, A.P.S.; PEREIRA, A.A.G.; BAYMA, J.C. Aleloquímico produzido pela gramínea forrageira Brachiaria humidicola. Planta Daninha, v.23, p.25-32, 2005.

SOUZA FILHO, A.P.S.; RODRIGUES, L.R.A.; RODRIGUES, T.J.D. Potencial alelopático de forrageiras tropicais: efeitos sobre invasoras de pastagens. Planta Daninha, v.15, p.53-60, 1997.

SUÁREZ-VÁSQUEZ, S.; WOOD, M.; NORTCLIFF, S. Crecimiento y fijación de nitrógeno por Arachis pintoi establecido con Brachiaria decumbens. Cenicafe, v.43, p.14-21, 1992.

VALENTIM, J.F.; CARNEIRO, J.daC.; SALES, M.F.L.Amendoim forrageiro cv. Belmonte: leguminosa para a diversificação das pastagens e conservação do solo no Acre. Rio Branco: Embrapa Acre, 2001. 18p. (Embrapa Acre. Circular Técnica, 43).

WALKLEY, A.; BLACK, I.A. An examination of the Degtjareff method for determining soil organic matter and a proposed modification of the chromic acid titration method. Soil Science, v.37, p.29-38, 1934.

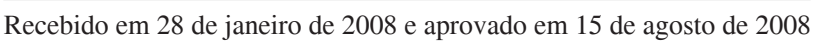


